\title{
Instruments for Measuring Incidents Related to Patient Safety in the Context of Paediatric Intensive Care - Protocol for a Scoping Review
}

\section{Helga Oliveira ( $\square$ helgacatarina@hotmail.com ) \\ Ricardo Rafael Marques \\ Escola Superior de Enfermagem de Lisboa \\ Maria Alice Santos Curado \\ Escola Superior de Enfermagem de Lisboa \\ Maria Filomena Gaspar \\ Escola Superior de Enfermagem de Lisboa}

Escola Superior de Enfermagem de Lisboa https://orcid.org/0000-0003-4981-8420

\section{Paulo Sousa}

Universidade Nova de Lisboa Escola Nacional de Saude Publica

\section{Protocol}

Keywords: paediatric intensive care, patient safety, measurement tool, incident, adverse event

Posted Date: February 19th, 2021

DOI: https://doi.org/10.21203/rs.3.rs-219186/v1

License: (c) (i) This work is licensed under a Creative Commons Attribution 4.0 International License. Read Full License

Version of Record: A version of this preprint was published at Systematic Reviews on January 25th, 2022. See the published version at https://doi.org/10.1186/s13643-022-01888-6. 


\section{Abstract}

Background: Patient safety is a fundamental principle of health care, but one of the biggest challenges currently faced and a serious public health problem, since the occurrence of adverse events is probably one of the main causes of morbidity and mortality worldwide. The vulnerability of the paediatric population, combined with the potentially dangerous context of intensive care, makes Paediatric Intensive Care Units services of particular complexity in matters of safety, where there is a greater likelihood of incidents with serious consequences. It is agreed that research on the topic of PS should start with the measuring of different types of harm that exist in the contexts, to identify high-risk areas and define priorities. For this, it is necessary to resort to a multiplicity of valid, reliable and specific measurement instruments and to learn their advantages and limitations.

Objectives: Identify and map in scientific literature the instruments for measuring incidents related to patient safety applicable in the context of paediatric intensive care.

Methods: This review will cover studies and documents that refer to all measurement instruments used in the field of patient safety in a context of paediatric intensive care. Published studies of a quantitative, qualitative or mixed nature and grey literature relevant to the topic will be included, in Portuguese, English or Spanish and produced since 2015. The sources of information include several databases and sources relevant to grey literature. The two authors will independently conduct the entire data selection process. The results of the research strategy will be presented in a PRISMA flowchart. The extracted data, after being organised in the extraction table, will be mapped in a descriptive and logical way, taking into account the defined review questions.

Discussion: The mapping of the tools in these protocol will allow to summarize the most widely used instruments, to know their specificities and to guide researchers to use the most appropriate measurement tools for their context, specifically, in paediatric intensive care.

Scoping Review Registration: This protocol is registered on the Open Science Framework, https://osf.io/dashboard, DOI https://doi.org/10.17605/OSF.IO/V435E.

\section{Background}

\section{Health Safety}

From a historical point of view, "Primum non Nocere”, or "First, do no harm”, evoked by Hippocrates, was the first reference to the subject of patient safety [PS] (1). Florence Nightingale, in an embryonic era for health care, also acknowledged that the conditions in which care is provided are defining $(2,3)$. It was this pioneer who first approached the dimension of quality, but it is Avedis Donabedian who is attributed with the first concrete definition, composed of the triad result, process and structure. Later, the Institute of Medicine [IOM] integrated safety as an inseparable pillar of quality, and the dimension of satisfaction was also added, from the perspective of patientcentred care (1).

To better understand this topic, it is important to clarify some key concepts of taxonomy defined by the World Health Organization [WHO] and translated by the General Directorate of Health (4):

- Patient Safety is reducing the risk of unnecessary harm, related to healthcare, to an acceptable minimum. Risk is the probability of an incident occurring; 
- Quality is the degree to which health services increase the likelihood of desired health outcomes and are consistent with current professional knowledge;

- An incident can be a reportable occurrence, a quasi-event, and an incident without harm or an incident involving harm (Adverse Events [AE]). Harm implies damage to the structure or functions of the body and/or any resulting harmful effects, including injury, suffering, disability or death, and may be physical, social or psychological;

- Error is the failure to execute a planned action according to the desired or the incorrect development of a plan.

The subject of patient safety has, in recent decades, become a central issue on health and society agendas the world over. After the revolutionary To Err is Human report carried out in 2000 by the IOM (5), which reported a remarkable number of deaths due to errors in the health system, several safety agencies were created, including the Agency for Healthcare Research and Quality, the Institute for Healthcare Improvement [IHI] and the World Alliance for Patient Safety. Since then, several studies have been carried out and bolstered the data published by the IOM (6). According to the WHO (7.8), harm to the patient currently represents the 3rd leading cause of death in the United States of America [USA] and it is estimated that one in ten patients suffers an event involving harm while receiving hospital care, of which about $50 \%$ would be preventable. The economic costs associated with medication errors total around $\$ 42$ billion, $15 \%$ of healthcare spending is derived from $\mathrm{AE}$, and security strategies represented savings of $\$ 28$ billion in the US between 2010 and 2015. At European level, it is estimated that $8-12 \%$ of hospitalised patients are subject to the occurrence of an $\mathrm{AE}(9)$.

As can be seen, PS is currently a serious public health problem that needs an effective response. The strategies adopted must be adaptable to local contexts and available resources (10) and, among the various proposed government actions, the following stand out: the creation of specialist agencies, the implementation of a national incident reporting system, the promotion of a safety culture and the involvement of all stakeholders. Therefore, it is important to define a benchmark framework that, based on the best evidence, integrates, articulates and guides the action of all stakeholders to reduce the occurrence of harm (11).

In Portugal, PS is an unavoidable subject, evident in several official documents, which reveal a concern to align national strategies with international guidelines. It is noteworthy that one of the National Health Plan's strategic axes foresees specific measures in the scope of safety, namely the implementation of a National Plan for the Safety of Patients 2015-2020 (12), which aims to support managers and clinicians in managing the risks associated with the provision of care (13).

Despite this growing concern, scientific production on this matter in the national context is still scarce. With regard to the epidemiological dimension of the problem, we highlight a study that revealed an AE incidence rate of $12.5 \%$ in hospitalisation incidents, of which $39.9 \%$ would be preventable. It should be noted that one of the limitations of this study is the non-inclusion of the paediatric population (14).

In short, the challenges in Portugal relate to: 1) the deeper epidemiological knowledge of $\mathrm{AE}$; 2) the uniformity of the notification systems and the articulation of the information systems, in order to allow a consistent comparison of data; 3 ) the paradigm shift in terms of security is seen as an investment and not an expense; 4) investing in research and strengthening partnerships between clinical and academic contexts; 5) and the introduction of the topic in initial and advanced training (15).

\section{Paediatric Safety}


Access to high quality health care is an essential human right (16). The right to safety has been reported in several significant documents in the field of Paediatrics, such as the Convention on the Rights of the Child (17) and the Notes to the Charter of the Hospitalised Child (18). Despite this fundamental right, several studies point to a high incidence rate of AE in Paediatrics, despite the limited and variable data in different hospital contexts.

It is estimated that approximately 70,000 children per year suffer some form of harm from health-related events (19). It is described that they are more prone to the occurrence of an AE and those who experienced it had a longer hospital stay, higher mortality rate and resulted in a greater institutional burden, which accurately reflects the human and economic impact of this problem (20-23).

Children have specific risk factors that make them more susceptible to harm and, according to several authors, contribute to about half of the events. These factors can help us understand some causes of AE and refer to: 1) physical characteristics, which increase the events with therapy, ventilation and vascular accesses; 2) developmental characteristics, which are related to events associated with communication, patient identification and monitoring; and 3) dependency level, which influences their participation in decision making and care (21, 2325).

\section{Safety in Paediatric Intensive Care}

The incidence of events varies according to the place where they occur, with factors underlying the patient themselves and with the type of care needed. Fragata (1) states that paediatric patients are more likely to experience an $\mathrm{AE}$ with a high severity potential and that, in intensive care, it is estimated that each suffers from one to two AE per day, which makes the Paediatric Intensive Care Units [PICU] a potentially lethal context. PICU is defined as a service for hospitalisation of patients aged between 1 month and 18 years of age, with serious and potentially reversible diseases, which can benefit from a more detailed observation than that which is usually available in general wards (26).

$\mathrm{AE}$ are a common problem in this context and, at international level, their incidence and typology is widely variable (27), which may be associated to the level of PICU, the methodology used, the type of incident involved and the awareness of professionals about the notification. As for the methodology, prospective approaches such as direct observation and surveillance may be used, or retrospective approaches like the review of documents or clinical processes and the analysis of incidents reported voluntarily in the notification systems (28). As there is no universal measurement instrument for PS, it is necessary to know the advantages and limitations of the chosen methods. The assessment of different types of harm requires a multiplicity of measures, and knowledge about their specificity, validity, reliability and applicability to different contexts is essential (28-31).

One of the most widely used methodologies for measuring AE is document review using the Trigger Tool (TT) (28, 32-34). This methodology consists of a retrospective review of clinical processes, in order to identify clues / triggers that suggest the occurrence of a certain damage resulting from an AE. This review is carried out by at least three reviewers trained in this methodology and takes place in two essential phases: 1) two primary reviewers, usually nurses, with vast knowledge and experience in the care context, make an independent review of the processes in order to detect the presence of the triggers; 2 ) a doctor authenticates the consensus of the primary reviewers and determines the severity level of the AE. This doctor, despite not carrying out the review of the process, must be available to answer questions that arise in the first phase $(33,35)$.

One of the main drivers of the use of TT was the IHI, which developed several tools for different clinical contexts. Specifically in Paediatrics, some tools have been developed in this line of methodology, of which the British and 
Swedish versions stands out $(32,36)$. In the context of PICU, a systematic literature review (32)was identified: the PICU trigger list (pilot study) (37), the PICU Trigger Tool (which assembled and validated other TT triggers) (38), and the PICU Trigger Tool (developed by Child Health Corporation of America).

A study carried out at a PICU that compares the TT methodology with the analysis of incidents reported voluntarily, concluded that the first is simple, efficient and robust and allows the detection of a greater number of AE. However, it does not detect near miss, diagnostic and omission errors and many types of medication errors, and it does not provide any feedback on the contributing factors (39). Bearing in mind that voluntary notification allows the overcoming of these limitations, this methodology, despite identifying only $10-20 \%$ of $A E(40)$, should be used complementarily.

With the multicentre study carried out by Agarwal et al as a reference (38) in 15 US PICU and using a TT, the incidence was $2 \mathrm{AE}$ per patient and significantly higher rates in patients who died. Another study that covered 23 PICU, also in the USA, concluded that two thirds of the incidents caused harm and that child-related factors were the strongest predictor of that damage. Despite the variability of studies, the most common AE were those related to medication, ventilation, catheters, equipment, infections associated with healthcare, poor regulation of alarms, lack of training and professional training and ineffective communication (1, 23, 27, 41-44). Despite medication errors being the most frequently mentioned, it was those associated with ventilation and vascular access that represented a higher level of harm (23).

This high incidence is due to the clinical complexity of the patients, the pressure associated with urgent situations, the length of stay, the invasive nature of the procedures, the therapeutic intensity and the use of complex equipment $(1,45)$. The costs associated with this problem must be properly analysed, so that the promotion of safety is seen as an investment and not an expense. As an example, it is estimated that the costs directly attributed to infections in the central vascular accesses are around $\$ 55,000$, accidental extubations to $\$ 101,000$ and the most serious $A E$ to $\$ 440,000(45)$.

In order to improve the safety of the care provided in this context, after understanding the causes mentioned above, it is necessary to identify the most effective solutions, with care bundles, checklists, double check systems, structured shift passages and point of care, rapid response systems and information and communication technologies being some of the resources suggested in the literature $(27,45-48)$. In order to assess the impact, specific quality indicators can be used to evaluate the outcomes, such as: mortality rate, rate of unplanned readmissions, the length of stay adjusted to the clinical severity and the rate of injuries, therapeutic errors, unscheduled extubations, incidents associated with vascular access, infections associated with healthcare and equipment-induced damage $(1,21,49)$. All of this research data should be disseminated by managers and direct care providers and solutions should be adequate for local contexts, to foster commitment to a practice based on levels of evidence (50).

\section{Objectives and Research Questions}

The objective of this Scoping Review [ScR] is to identify and map in the scientific literature the instruments for measuring incidents related to patient safety applicable in the context of paediatric intensive care.

The defined review questions are: 
1. What instruments are used to measure incidents related to patient safety in the context of paediatric intensive care?

2. What instruments can measure near miss and harmless events related to patient safety in the context of paediatric intensive care? What instruments allow the specific measurement of adverse events related to patient safety in the context of paediatric intensive care? Can these measurement tools be used for all types of incidents and what are their mains characteristics?

3. Is there evidence of the effectiveness of the application of these methods to improve patient safety?

\section{Methods}

The present protocol is reported in accordance with the reporting guidance provided in the Preferred reporting items for systematic reviews and meta-analysis protocols (PRISMA-P) $(51,52)$ and the PRISMA extension for Scoping Reviews (PRISMA-ScR) (53).

\section{Eligibility Criteria}

\section{Participants}

This ScR will include all studies, which refer to instruments for measuring incidents related to patient safety, whose participants are children and young people hospitalised in the context of paediatric intensive care.

\section{Concept}

The phenomenon of interest for a ScR is related to the instruments for measuring incidents related to patient safety in the context of paediatric intensive care.

\section{Context}

The defined context for a ScR is all paediatric intensive care units, regardless of their level of care activity, their polyvalent or specific typology, the type of hospital unit they belong to or their geographical location.

\section{Study Designs}

This ScR will cover all scientific articles that include studies on the subject, of a quantitative, qualitative or mixed nature and published and unpublished literature reviews (grey literature). Analytical documents (reports from reputable organisations, expert opinions or comments) that report or analyse aspects considered relevant to the subject in question will also be considered.

The studies may result from a single or multidisciplinary view (nursing, medicine, psychology, etc.). From a linguistic point of view, documents will be limited to Portuguese, English and Spanish and timewise, documents published from 2015 onwards will be included. However, after this first phase of research, studies and documents prior to 2015 but which contain measurement instruments relevant to the context in question may be considered.

\section{Information Sources}

To identify documents potentially relevant to the $\mathrm{ScR}$, and in order to increase the sensitivity of the research, two types of information sources will be used: 
1. Electronic databases - MEDLINE Complete, CINHAL Complete, MedicLatina and Cochrane Library (Cochrane Database of Systematic Reviews) via EBSCO; Science Direct and Scopus for Elsevier publications; Joanna Briggs Institute EBP Database via OVID; BioMed Central; and Scientific Electronic Library Online (SciELO Portugal and Brazil);

2. Other documents, namely: documents included in the Open Access Scientific Repository of Portugal; documents issued by the main organisations focused on patient safety $(\mathrm{WHO}, \mathrm{AHRQ}, \mathrm{IHI}$, National Patient Safety Agency, Joint Commission International, National Quality Forum and PROQUALIS), some of which are included in the "Gray Matters: a practical tool for searching health -related grey literature "that the Canadian Agency for Drugs and Technologies in Health outlined for approaching grey literature research (54). These documents may include reports, guidelines or opinion articles.

\section{Search Strategy}

The research strategy defined for this ScR involves three distinct stages:

1. Initial research carried out in a selection of relevant databases (MEDLINE and CINAHL), to analyse and select the main terms used (indexed and in natural language) in the titles and abstracts of articles related to patient safety in a paediatric intensive care context;

2. Research in each of the previously-mentioned sources of information, using the terms selected in the previous step and adapting them to each one specifically. After reading the titles and abstracts, two reviewers will select and read in full the documents that meet the eligibility criteria;

3. Analysis of the reference list of the selected documents, to identify additional bibliography.

The design of the search strategy carried out at MEDLINE with the respective selected terms and defined limits is found in an additional file.

The design of the research strategy and the selection of documents in the second stage will be carried out by both reviewers, independently and using previously established screening questions.

\section{Data Charting Process}

\section{Data management}

The selected documents will be uploaded to the Covidence web tool, which, in partnership with Cochrane, allows the optimisation of the systematic review process and facilitates collaboration between reviewers. For the management of references, the Mendeley application will be used.

\section{Data selection process}

The reviewers will independently carry out the four stages of data selection: identification, selection, eligibility and inclusion. In case of doubt, a debate will take place and, if necessary, a third reviewer will be contacted.

\section{Data collection process}

To gather the data collected in each of the selected documents, a chart was created, validated by the reviewers, which will group the most relevant information and answer the defined review questions, as well as the characteristics of the studies / documents. This selection is an interactive process and as such the chart will be continuously adjusted as the extraction proceeds. If a significant number of studies / documents are selected, a pilot test will be carried out to check the adequacy of the chart. 


\section{Critical appraisal of individual sources of evidence}

Quality assessment will not be carried out, as it is not a mandatory criterion for a ScR (53) and its aim is to encompass as much information about available measuring instruments.

\section{Synthesis of Results}

The results of the research strategy will be presented in the PRISMA flowchart. The extracted data, after being organized in the extraction chart, will be mapped in a descriptive and logical way, taking into account the defined review questions. Thus, a summary is sought that identifies the instruments for measuring incidents related to patient safety in the context of paediatric intensive care and that summarises their characteristics, specificities and limitations. Additionally, the results related to the characterisation of studies and documents and demographic aspects will be presented graphically.

\section{Discussion}

The vulnerability of the paediatric population, combined with the potentially dangerous context of intensive care, makes PICU services of particular complexity in matters of safety, where there is a greater likelihood of incidents with serious consequences. To identify high-risk areas and define priorities it is necessary to resort to a multiplicity of measurement instruments.

As there is no universal measurement instrument for PS, it is necessary to know the advantages and limitations of the chosen methods. The assessment of different types of harm requires a multiplicity of measures, and knowledge about their specificity, validity, reliability and applicability to different contexts is essential.

The mapping of tools in these protocol will allow to summarize the most widely used instruments, to know their specificities and to guide researchers to use the most appropriate measurement tools for their context, specifically, in paediatric intensive care.

\section{Limitations}

Limited access to information sources and linguistic and time limits may exclude some relevant sources, but it is intended that additional research can overcome this limitation.

\section{Abbreviations}

PS: patient safety; IOM: Institute of Medicine; WHO: World Health Organization; AE: adverse events; IHI: Institute for Healthcare Improvement; USA: United States of America; PICU: paediatric intensive care units; TT: trigger tool; ScR: Scoping Review.

\section{Declarations}

\section{Ethics approval and consent to participate}

Not applicable. 


\section{Consent for publication}

Not applicable.

\section{Availability of data and materials}

Not applicable.

\section{Competing interests}

The authors declare that they have no competing interests.

\section{Funding}

Not applicable.

\section{Authors' contributions}

$\mathrm{HO}$ and RRM conceived this review and drafted the protocol under the supervision of MASC, MFG e PS. All authors of the manuscript have read and agreed to its content and are accountable for all aspects of the accuracy and integrity of the final version.

\section{Acknowledgements}

Not applicable.

\section{References}

1. Fragata J. Segurança dos Doentes - Uma Abordagem Prática. $1^{\text {a }}$ Edição. Lisboa: LIDEL - edições técnicas; 2011.

2. Abreu C. O erro humano no contexto dos cuidados de enfermagem. In: Queirós P, editor. Enfermagem de Nightingale aos dias de hoje 100 anos. Coimbra: Unidade de Investigação da Escola Superior de Enfermagem de Coimbra; 2012. p. 247-64.

3. Fernandes A. Segurança do doente: velho desígnio, novos desafios. A mudança de paradigma cultural nas organizações de saúde. In: Queirós P, editor. Enfermagem de Nightingale aos dias de hoje 100 anos. Coimbra: Unidade de Investigação da Escola Superior de Enfermagem de Coimbra; 2012. p. 265-88.

4. Direção-Geral da Saúde. Estrutura Concetual da Classificação Internacional sobre Segurança do Doente [Internet]. Lisboa; 2011. Available from: http://www.dgs.pt/departamento-da-qualidade-na-saude.aspx

5. Institute of Medicine. To Err is Human: Building a Safer Health System. Kohn L, Corrigan J, Donaldson M, editors. Washington DC: National Academy of Sciences; 2000. 1-312 p.

6. World Health Organization. World Alliance for Patient Safety: Forward Programme [Internet]. Geneva; 2005. Available from: http://www.who.int/patientsafety/en/brochure_final.pdf 
7. World Health Organization. Patient Safety: Making health care safer. Geneva; 2017.

8. World Health Organization. 10 facts on patient safety [Internet]. 2019 [cited 2019 Oct 24]. Available from: https://www.who.int/features/factfiles/patient_safety/en/

9. Comissão Europeia. Patient safety and quality of care [Internet]. Special Eurobarometer 411. 2014. Available from: http://ec.europa.eu/public_opinion/archives/ebs/ebs_411_en.pdf

10. World Health Organization. Patient safety research: a guide for developing training programmes [Internet]. Geneva; 2012. Available from: http://apps.who.int/iris/bitstream/10665/75359/1/9789241503440_eng.pdf

11. Sousa P. Patient Safety: A Necessidade de uma Estratégia Nacional. Acta Med Port. 2006;19:309-18.

12. Direção-Geral da Saúde. Plano Nacional de Saúde - Revisão e Extensão a 2020 [Internet]. Lisboa; 2015 [cited 2019 Apr 13]. Available from: http://1nj5ms2/li5hdggbe3mm7ms5-wpengine.netdnassl.com/files/2015/06/Plano-Nacional-de-Saude-Revisao-e-Extensao-a-2020.pdf.pdf

13. Ministério da Saúde. Despacho n. ${ }^{\circ}$ 1400-A/2015: Plano Nacional para a Segurança dos Doentes 2015-2020. In: Diário da República $2^{\mathrm{a}}$ série - N 28 - 10 de fevereiro de 2015. 2015. p. 3882-(2-10).

14. Sousa P, Uva AS, Serranheira F, Uva MS, Nunes C. Patient and hospital characteristics that influence incidence of adverse events in acute public hospitals in Portugal: A retrospective cohort study. Int J Qual Heal Care. 2018;30(2):132-7.

15. Sousa P, Uva A de S, Serranheira F. Investigação e Inovação em Segurança do Paciente. Rev Port Saúde Pública [Internet]. 2010;10:89-95. Available from: http://hdl.handle.net/10362/19760

16. Comissão Europeia. Patient Safety - Making it Happen! Luxembourg Declaration on Patient Safety [Internet]. Luxemburgo; 2005. Available from: http://ec.europa.eu/health/ph_overview/Documents/ev_20050405_rd01_en.pdf

17. UNICEF. A Convenção sobre os Direitos da Criança [Internet]. 1990. Available from: http://www.unicef.pt/docs/pdf_publicacoes/convencao_direitos_crianca2004.pdf

18. Instituto de Apoio à Criança. Anotações Carta da Criança Hospitalizada. In: Vasco F, Levy ML, Cepêda T, editors. $2^{a}$. Lisboa: Instituto Apoio à Criança; 2009. p. 1-40. Available from: http://issuu.com/iacrianca/docs/anotacoes_carta_da_crian_a_hospitalizada_2009/1?e=0

19. Lemon V, Stockwell DC. Automated detection of adverse events in children. Pediatr Clin North Am [Internet]. 2012 Dec;59(6):1269-78. Available from: http://www.ncbi.nlm.nih.gov/pubmed/23116524

20. Runy LA. Pediatric safety: caring for children raises different quality and patient safety issues. H\&HN Hosp Heal Networks [Internet]. 2009;83(5):1-5. Available from: http://web.a.ebscohost.com/ehost/detail/detail? vid=6\&sid=08c274d7-b83c-4b50-a292-

532f4dbfdc92@sessionmgr4005\&hid=4107\&bdata=JnNpdGU9ZWhvc3QtbGI2ZQ==\#db=rzh\&AN=2010313737

21. Lacey S, Smith JB, Cox K. Pediatric Safety and Quality. In: Hughes RG, editor. Patient Safety and Quality: An Evidence-Based Handbook for Nurses [Internet]. Rockville: Agency for Healthcare Research and Quality; 2008. p. 1-30. Available from: http://www.ncbi.nlm.nih.gov/books/NBK2662/

22. Muething SE, Goudie A, Schoettker PJ, Donnelly LF, Goodfriend MA, Bracke TM, et al. Quality Improvement Initiative to Reduce Serious Safety Events and Improve Patient Safety Culture. Pediatrics. 2012;130(2):e42331.

23. Skapik JL, Pronovost PJ, Miller MR, Thompson DA, Wu AW. Pediatric Safety Incidents From an Intensive Care Reporting System. J Patient Saf. 2009;5(2):95-101. 
24. Woods D, Holl J, Shonkoff J, Mehra M, Ogata E, Weiss K. Child-specific risk factors and patient safety. J Patient Saf. 2005;1(1):17-22.

25. Fisher E. Patient Safety in Pediatrics. In: Agrawal A, editor. Patient Safety: A Case-Based Comprehensive Guide. Nova York: Springer Science + Business Media; 2014. p. 249-62.

26. Ministério da Saúde. Avaliação da situação nacional das unidades de cuidados intensivos. $N^{\circ} 59,2^{\mathrm{a}}$ Série Portugal: Diário da República; p. 1-459.

27. Ullman A, Long D, Horn D, Woosley J, Coulthard M. The KIDS SAFE Checklist for Pediatric Intensive Care Units. Am J Crit Care. 2013;22(1):61-9.

28. Wu A. Sessão 3: Medir o dano [Internet]. Investigação em Segurança do Paciente/Doente - Curso Introdutório. 2013 [cited 2019 Jun 1]. Available from:

https://www.who.int/patientsafety/research/online_course_portuguese/en/

29. Vincent C, Burnett S, Carthey J. The measurement and monitoring of safety. Londres; 2013.

30. The UK Improvement Alliance. Measurement and Monitoring of Safety Framework e-guide Better Questions Safer Care. Bradford; 2017.

31. The Health Foundation. A framework for measuring and monitoring safety: A practical guide to using a new framework for measuring and monitoring safety in the NHS Contents. Londres; 2016.

32. Hibbert PD, Molloy CJ, Hooper TD, Wiles LK, Runciman WB, Lachman P, et al. The application of the global trigger tool: A systematic review. Int J Qual Heal Care. 2016;28(6):640-9.

33. Griffın F, Resar R. IHI Global Trigger Tool for Measuring Adverse Events (Second Edition) [Internet]. IHI Innovation Series white paper. Cambridge, Massachusetts: Institute for Healthcare Improvement; 2009. p. 146. Available from: http://www.ihi.org/resources/Pages/IHIWhitePapers/IHIGlobalTriggerToolWhitePaper.aspx

34. Sousa P, Uva A de S, Serranheira F, Leite E, Nunes C. Segurança do Doente - Eventos adversos em hospitais portugueses: estudo piloto de incidência, impacte e evitabilidade [Internet]. Lisboa; 2011. Available from: https://www.ensp.unl.pt/invest-desenvolv-inov/projectos/brochura_estudo_ea2011.pdf

35. NHS - Institute for Innovation and Improvement. The Paediatric Trigger Tool - User guide [Internet]. 2014. Available from: https://bmjopen.bmj.com/content/suppl/2014/07/03/bmjopen-2014-005066.DC1/bmjopen2014-005066supp2.pdf

36. Institute for Healthcare Improvement. Trigger Tools [Internet]. 2019 [cited 2019 Jun 14]. Available from: http://www.ihi.org/Topics/TriggerTools/Pages/default.aspx

37. Larsen GY, Donaldson AE, Parker HB, Grant MJC. Preventable harm occurring to critically ill children. Pediatr Crit Care Med. 2007;8(4):331-6.

38. Agarwal S, Classen D, Larsen G, Tofil NM, Hayes LW, Sullivan JE, et al. Prevalence of adverse events in pediatric intensive care units in the United States. Pediatr Crit Care Med. 2010;11(5):568-78.

39. Hooper AJ, Tibballs J. Comparison of a Trigger Tool and voluntary reporting to identify adverse events in a paediatric intensive care unit. Anaesth Intensive Care. 2014;42(2):199-206.

40. Sari ABA, Sheldon TA, Cracknell A, Turnbull A. Sensitivity of routine system for reporting patient safety incidents in an NHS hospital: Retrospective patient case note review. Br Med J. 2007;334:79-81.

41. Martin J. Paediatric Intensive Care Safety Package [Internet]. Birmingham; 2013. Available from: http://www.pipsqc.org/Portals/0/BCH PICU Safety Package2[smallpdf.com].pdf

42. Schatkoski AM, Wegner W, Algeri S, Pedro ENR. Segurança e proteção à criança hospitalizada: revisão de literatura. Rev Lat Am Enfermagem [Internet]. 2009;17(3):410-416. Available from: www.eerp.usp.br/rlae 
43. Nichter MA. Medical errors affecting the pediatric intensive care patient: incidence, identification, and practical solutions. Pediatr Clin North Am [Internet]. 2008 Jun [cited 2014 May 19];55(3):757-77, xii. Available from: http://www.ncbi.nlm.nih.gov/pubmed/18501764

44. Bauer P, Hoffmann RG, Bragg D, Scanlon MC. Perceptions of risk to patient safety in the pediatric ICU, a study of American pediatric intensivists. Saf Sci [Internet]. 2013 Mar [cited 2014 Jul 23];53:160-7. Available from: http://linkinghub.elsevier.com/retrieve/pii/S0925753512002299

45. Wolfe HA, Mack EH. Making care better in the pediatric intensive care unit. Transl Pediatr. 2018;7(4):267-74.

46. Chaboyer W, Hewson-Conroy K. Quality and Safety. In: Elliot D, Aitken L, Chaboyer W, editors. ACCCN's Critical Care Nursing [Internet]. 2nd ed. Chatswood: Elsevier Australia; 2012. p. 38-56. Available from: www.Ipnh.go.th/web_nurse/cop_ccn/emer.doc

47. Mckelvie BL, Mcnally JD, Menon K, Marchand MGR, Reddy DN, Creery WD. A PICU patient safety checklist: rate of utilization and impact on patient care. Int J Qual Heal Care. 2016;28(3):371-5.

48. Lyren A, Brilli RJ, Zieker K, Marino M, Muething S, Sharek PJ. Children's Hospitals' Solutions for Patient Safety Collaborative Impact on Hospital-Acquired Harm. Pediatrics. 2017;140(3):1-12.

49. Scanlon MC, Mistry KP, Jeffries HE. Determining pediatric intensive care unit quality indicators for measuring pediatric intensive care unit safety. Pediatr Crit Care Med. 2007;8(2 SUPPL.):3-10.

50. Wu A. Sessão 7: Traduzir a evidência em Cuidados de Saúde mais Seguros [Internet]. Investigação em Segurança do Paciente/Doente - Curso Introdutório. 2013 [cited 2019 Jun 1]. Available from: https://www.who.int/patientsafety/research/online_course_portuguese/en/

51. Moher D, Shamseer L, Clarke M, Ghersi D, Liberati A, Petticrew M, et al. Preferred reporting items for systematic review and meta-analysis protocols (PRISMA-P) 2015 statement. Vol. 4, Systematic Reviews. 2015.

52. Shamseer L, Moher D, Clarke M, Ghersi D, Liberati A, Petticrew M, et al. Preferred reporting items for systematic review and meta-analysis protocols (PRISMA-P) 2015: elaboration and explanation. BMJ. 2015;349(g7647):125.

53. Tricco AC, Lillie E, Zarin W, O’Brien K, Colquhoun H, Levac D, et al. PRISMA Extension for Scoping Reviews (PRISMA-ScR): Checklist and Explanation. Ann Intern Med. 2018;169(7):1-7.

54. Canadian Agency for Drugs and Technologies in Health. Grey Matters: a practical tool for searching healthrelated grey literature. 2015.

\section{Supplementary Files}

This is a list of supplementary files associated with this preprint. Click to download.

- ScopingReviewProtocolBMCSRAdditionalfile1.docx

- ScopingReviewProtocolBMCSRAdditionalfile2.docx

- ScopingReviewProtocolBMCSRAdditionalfile3.docx

- ScopingReviewProtocolBMCSRAdditionalfile4.docx 